\title{
BALANÇO ENERGÉTICO E EMISSÕES DE GASES DE EFEITO ESTUFA DO PROCESSO DE PRODUÇÃO DE ETANOL: UM ESTUDO DE CASO
}

\author{
Mônica Joelma do Nascimento Anater ${ }^{1}$, Jessika Rodrigues do Nascimento ${ }^{2}$, Eduardo \\ Mirko Valenzuela Turdera ${ }^{3}$, Carlos Roberto Sanquetta ${ }^{4}$, Ana Paula Dalla Corte ${ }^{5}$ \\ ${ }^{1}$ Mestranda do Programa de Pós-graduação em Bioenergia da Universidade \\ Federal do Paraná (anaater@hotmail.com) Curitiba-Brasil \\ ${ }^{2}$ Engenheira de Energia pela Universidade Federal da Grande Dourados \\ ${ }^{3}$ Professor Doutor da Faculdade de Engenharia da Universidade Federal da \\ Grande Dourados \\ ${ }^{4}$ Professor Doutor da Faculdade de Engenharia Florestal da Universidade Federal \\ do Paraná \\ ${ }^{5}$ Professora Doutora da Faculdade de Engenharia Florestal da Universidade \\ Federal do Paraná
}

\section{Recebido em: 03/10/2016 - Aprovado em: 21/11/2016 - Publicado em: 05/12/2016 DOI: 10.18677/EnciBio_2016B_150}

\begin{abstract}
RESUMO
Um dos principais métodos para verificar o quão vantajoso é a utilização de um biocombustível é por meio do balanço energético, que verifica se a quantidade de energia gerada pelo biocombustível é menor ou maior do que a energia empregada na sua produção. O objetivo principal do trabalho foi analisar o balanço energético e as emissões do processo de produção do etanol através do estudo de caso de uma usina localizada no estado de Mato Grosso do Sul, que produz tanto açúcar e álcool (etanol) quanto energia elétrica para ser injetada na rede, porém, foram analisadas apenas informações acerca da produção do etanol pela usina. A usina forneceu dados como o consumo dos insumos agrícolas, gasto médio de combustível para uso em plantações $(\mathrm{L} / \mathrm{km})$ e total de etanol gerado. Analisada a usina e baseados em referências bibliográficas, foi calculado o gasto energético total da indústria para a produção de etanol, o que deu como resultado $21.787,8 \mathrm{MJ}$ ha ${ }^{-1}$. Já a produção

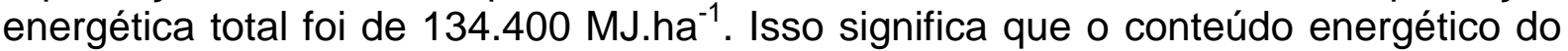
etanol é 6,2 vezes superior à energia gasta na sua produção para esta usina. Este valor está condizente com a literatura especializada consultada. O balanço de emissões foi extremamente positivo, onde foi verificado um total evitado de 982.271,02 $\mathrm{tCO}_{2 \text { eq }}$ em toda área da usina.
\end{abstract}

PALAVRAS-CHAVE: cana-de-açúcar, energia, setor sucroenergético.

\section{ENERGY BALANCE AND GHG EMISSIONS OF ETHANOL PRODUCTION PROCESS: A CASE STUDY}

\begin{abstract}
One of the methods to verify the advantage of using a biofuel in terms of energy is energy balance, which checks whether the amount of power generated by the biofuel is smaller or larger than the energy used in their production. The objective of this study was to analyze the energy balance and greenhouse gas emissions (GHG) from
\end{abstract}


the ethanol production process through a case study at a power plant in the state of Mato Grosso do Sul. The plant produces sugar and alcohol (ethanol) as well as electric power to be injected into the interconnected system, however, only analyzed information about the production of ethanol by the plant. For this case study, the plant provided consumption data of agricultural inputs, average consumption of fuel for use in plantations $(\mathrm{L} / \mathrm{km})$ and total ethanol produced. We calculated the total energy expenditure of industry for the production of ethanol, which resulted in 21.787,8 MJ.ha $^{-1}$. The total energy production was $134.400 \mathrm{MJ}^{-} \mathrm{ha}^{-1}$ of sugarcane. This means that the energy content of ethanol is 6.2 times the energy expended in production to this plant. This value is consistent with the literature consulted. Emissions balance was positive, resulting in $982,271.02 \mathrm{tCO}_{2 \text { eq }}$ avoided in every planted area.

KEYWORDS: sugarcane, energy, sugarcane industry.

\section{INTRODUÇÃO}

O balanço energético é um termo utilizado para indicar a relação entre a energia investida na produção e a contida, no caso, no biocombustível. Na maioria das culturas, a energia investida provém quase que totalmente de origem fóssil, e com a diminuição das reservas destes combustíveis é cada vez maior a necessidade de um estudo desta relação energética. Quanto maior a utilização de combustíveis fósseis para a produção de biocombustíveis, menos renováveis estes serão. 0 biocombustível não se torna vantajoso quando se utiliza mais energia fóssil na sua produção do que a própria energia contida neste biocombustível (ABRAMOVAY, 2009).

No balanço energético, geralmente são considerados: a energia empregada na produção do biocombustível, a demandada nos processos de fabricação e a requerida na obtenção de outros insumos utilizados no processo (CLAUDINO \& TALAMINI, 2012). No caso dos biocombustíveis, este contempla desde o óleo diesel utilizado pelos tratores, até a energia incorporada em maquinários, fertilizantes, defensivos, sementes e demais insumos empregados.

Um dos maiores exemplos de dependência de combustíveis fósseis para a produção de biocombustíveis é a utilização de adubos químicos nitrogenados que são derivados do petróleo. Ao longo da cadeia do etanol, são necessários inúmeros insumos, como potássio, fósforo, nitrogênio, herbicidas para o preparo da terra, e gasto de combustível para transporte da cana para a usina e o transporte entre a usina e o centro de distribuição do combustível (TURDERA, 2013).

Enquanto o etanol de cana-de-açúcar possui um balanço energético, em geral, bastante positivo, o etanol de outras matérias-primas, como o milho ou a beterraba, não passa de duas unidades (ABRAMOVAY, 2009). O balanço energético do milho é de apenas 1,2, o que faz com que o balanço energético para a produção do bioetanol proveniente do milho seja praticamente equiparada, ou seja, por cada unidade de energia gasta se recupera uma unidade contida (OLIVEIRA et al. 2014). Desta forma se deduz que não há vantagem tecnológica na produção do bioetanol proveniente do milho, enquanto isso o balanço energético do etanol de cana-deaçúcar está sempre próximo ou acima de 4.

O balanço energético varia conforme o sistema de produção adotado, podendo ser mais ou menos positivo com o nível de modernidade das tecnologias empregadas. Atualmente é considerada como uma média de balanço energético para o etanol de cana-de-açúcar o valor 8, o qual é condizente com o encontrado 
por MACEDO et al. (2004), que fez um balanço baseado nas médias de consumos de energia e insumos na produção do etanol e obteve o valor de 8,3 para usinas produtoras de etanol no Brasil.

Segundo SANTOS et al. (2012), o etano de primeira geração, obtido por meio do caldo de cana-de-açúcar, é o único combustível, que atualmente tem potencial para atender a crescente demanda mundial com um custo relativamente baixo e com menores teores de poluentes. Os processos que mais emitem gases de efeito estufa na cadeia de produção do etanol dizem respeito à produção da cana, como transporte, colheita e plantio, decomposição de fertilizantes, e em muitas vezes, queima da palha (MACEDO et al. 2004). Mesmo assim, segundo ABRAMOVAY (2009), várias estimativas baseadas no ciclo de vida do etanol mostram que este reduz em até $90 \%$ as emissões quando comparado com a gasolina.

Segundo COELHO et al. (2016), os resíduos do processo de produção de etanol podem ser excelentes fontes alternativas de energia, tais como torta de filtro, vinhaça e o bagaço. O bagaço é um dos resíduos mais importantes, já que pode ser utilizado na queima em caldeiras, gerando calor e eletricidade no processo de cogeração. Ao utilizar esses resíduos, o balanço energético torna-se ainda mais positivo, já que a energia investida na produção da cana é aproveitada ao máximo.

Este trabalho teve como objetivo analisar o balanço energético e o balanço de emissões do processo de produção de etanol de uma usina moderna do estado de Mato Grosso do Sul e verificar se o sistema produtivo de alta tecnologia está influenciando positivamente no balanço energético.

\section{MATERIAL E MÉTODOS}

A usina estudada está localizada no estado de Mato Grosso do Sul e na safra (2012/2013) colheu 4,5 milhões de toneladas de cana-de-açúcar, transformadas em 330 mil toneladas de açúcar e $150 \mathrm{mil} \mathrm{m}^{3}$ de etanol anidro. A mesma usina possui $100 \%$ de corte mecanizado, limpeza de cana a seco, moenda $100 \%$ eletrificada, agricultura de precisão com piloto automático, dois geradores com potência de 122,2 MW e detêm uma área de plantio de 60.000 ha.

Os dados para elaboração deste trabalho foram obtidos in loco com responsáveis do setor agrícola da usina, que preferiu não ter divulgado o seu nome. Os dados fornecidos foram os seguintes: quantidade de insumos utilizados pela planta energética para produção do etanol, quantidade de combustível fóssil consumido, e produtividade da fabricação de álcool por tonelada de cana.

A partir destes dados, tomando em consideração que cada insumo ou combustível possui uma equivalência energética, fez se uma análise do quanto de energia foi gasto para a produção do etanol. Equivalência energética é dita como a energia gasta para produzir 1 unidade de cada insumo, produto ou processo que é utilizado no processo de produção do etanol. Assim, para a obtenção do balanço energético, foram utilizados equivalentes de energia produzida (saída) e energia investida na produção (entrada) conforme os trabalhos de MACEDO et al. (2008) e OLIVEIRA et al. (2005).

O consumo energético na cadeia do etanol se deve ao gasto energético para a produção do mesmo. Neste trabalho, foram considerados os seguintes consumos energéticos, descritos na equação 1:

$$
\text { Consumo energético total }=G_{\text {comb }}+G_{\text {fert }}+G_{\text {edif }}+G_{\text {lubr }}+G_{\text {equip }}
$$


Onde:

$\mathrm{G}_{\text {comb }}=$ Gasto de combustíveis (principalmente diesel) na lavoura, no transporte da cana até a usina e no transporte do etanol até a distribuidora;

$\mathrm{G}_{\text {fert }}=$ Produção de insumos e fertilizantes (potássio, fosfato e nitrogênio) para o melhoramento do solo;

$G_{\text {edif }}=$ Gasto energético na construção da usina para a produção de etanol;

$\mathrm{G}_{\text {lubr }}=$ Gasto energético pela utilização de produtos químicos e lubrificantes;

$\mathrm{G}_{\text {equip }}=$ Gasto energético da construção dos equipamentos utilizados ao longo do processo de produção do etanol.

Já a produção energética total é dada por:

Produção energética total $\left(M J \cdot h a^{-1}\right)=\left(P_{\text {usina. }} \cdot P_{\text {etanol }} \cdot E_{\text {qe }}\right)$

Eq. 2

Onde:

$\mathrm{P}_{\text {usina }}=$ Produtividade da usina, em tonelada de cana por hectare $\left(\mathrm{tc}^{1} \cdot \mathrm{ha}^{-1}\right)$;

$P_{\text {etanol }}=$ Produção de etanol por tonelada de cana (L.tc $\left.{ }^{-1}\right)\left(80 L^{\prime} \cdot c^{-1}\right.$, fornecido);

$E q_{e}=$ Equivalente energético do etanol (22,4 MJ.L-1) (MACEDO et. al, 2004)

Neste trabalho, não foi considerada a parcela correspondente à geração de bioeletricidade excedente devido a não disponibilização desses dados por parte da usina. $O$ valor adimensional do balanço energético é dado pela relação entre a produção energética total e o consumo energético total, tal como na equação 3.

$$
\text { Balanço energético }=\frac{\text { Produção energética total }}{\text { Consumo energético total }}
$$

Quanto maior o valor da relação, melhor o balanço energético, significando um baixo consumo de energia para a produção do biocombustível. Por outro lado, um baixo valor de balanço energético significa um alto consumo de energia para a sua produção, indicando que o biocombustível não é interessante do ponto de vista energético.

Para obter os valores das emissões geradas no processo de produção do etanol para esta usina, utilizaram-se valores de equivalência de emissões para os insumos, já que cada produto ou processo emite uma quantidade de $\mathrm{CO}_{2}$. Baseouse em literaturas como MACEDO et al. (2008), OLIVEIRA et al. (2005) e IPCC (2014) para valores de equivalências de emissões. Assim, foi possível quantificar as emissões do processo de produção de etanol para esta usina. Alguns dados como informações sobre a maquinaria e a torta de filtro não foram fornecidos, desta forma, dados de literaturas foram considerados para estimação das emissões.

A parcela correspondente à fixação de carbono na biomassa foi considerada neutra ou zero, já que o carbono fixado durante o crescimento da planta é liberado novamente durante a produção do etanol e na utilização final do etanol e do bagaço (MACEDO et al., 2004). As únicas parcelas consideradas como emissões evitadas foram do uso do etanol em substituição da gasolina em veículos automotivos, e do uso do bagaço para produção de energia excedente em substituição ao óleo combustível, que, teoricamente, seria utilizado caso não houvesse utilização do

${ }^{1}$ tc = tonelada de cana. 
bagaço. Assim, subtraindo-se as emissões evitadas das não evitadas, é possível obter um balanço de emissões para a produção de etanol na usina estudada.

\section{RESULTADOS E DISCUSSÃO}

\section{Balanço energético}

Os valores fornecidos pela usina e as equivalências energéticas utilizadas estão descritos na Tabela 1. Segundo a usina, 100\% de sua plantação é orgânica, ou seja, não são utilizados herbicidas, pesticidas ou inseticidas na plantação.

TABELA 1- Gasto energético no processo de produção do etanol gerado pela usina estudada com base na utilização de insumos e em seu equivalente energético.

\begin{tabular}{|c|c|c|c|}
\hline Componente & Quantidade por hectare & $\begin{array}{l}\text { Demanda de } \\
\text { energia (MJ) }\end{array}$ & $\begin{array}{c}\text { Gasto } \\
\text { energético } \\
\left(\mathrm{MJ} . \mathrm{ha}^{-1}\right) \\
\end{array}$ \\
\hline Nitrogênio & $100,00^{\mathrm{a}} \mathrm{kg}$ & \multirow{9}{*}{$\begin{array}{c}56,3^{\mathrm{C}} \text { por } \mathrm{kg} \\
7,5^{\mathrm{C}} \text { por } \mathrm{kg} \\
7,0^{\mathrm{C}} \text { por } \mathrm{kg} \\
1,71^{\mathrm{d}} \text { por } \mathrm{kg} \\
15,6^{\mathrm{d}} \text { por tonelada } \\
355,6^{\mathrm{C}} \text { por } \mathrm{kg} \\
358,0^{\mathrm{C}} \text { por } \mathrm{m}^{3} \\
0,11^{\mathrm{d}} \text { por } \\
\text { trabalhador } \\
38,3^{\mathrm{C}} \text { por litro }\end{array}$} & 5.630 \\
\hline Fosfato $\left(\mathrm{P}_{2} \mathrm{O}_{5}\right)$ & $25,00^{\mathrm{a}} \mathrm{kg}$ & & 187,5 \\
\hline Óxido de Potássio $\left(\mathrm{K}_{2} \mathrm{O}\right)$ & $140,00^{\mathrm{a}} \mathrm{kg}$ & & 980 \\
\hline Calcário & $4.000^{\mathrm{a}} \mathrm{kg}$ & & 6.840 \\
\hline Sementes & $1,62^{\mathrm{b}}$ toneladas & & 25,27 \\
\hline Herbicidas litros & $0^{\mathrm{a}} \mathrm{kg}$ & & 0 \\
\hline Pesticidas & $0^{\mathrm{a}} \mathrm{kg}$ & & 0 \\
\hline Trabalho & $0,04^{\mathrm{a}}$ trabalhadores & & 0,0044 \\
\hline Diesel combustível & $165,00^{\mathrm{a}}$ litros & & $6.319,5$ \\
\hline Gasto na etapa agrícola & & & $19.982,3$ \\
\hline Químicos e lubrificantes & & & $1.477,5^{\mathrm{c}}$ \\
\hline Construção e edifícios & & & $37,5^{\mathrm{c}}$ \\
\hline Equipamentos & & & $292,5^{c}$ \\
\hline Gasto energético total & & & $21.787,8$ \\
\hline $\begin{array}{l}\text { Fonte: }{ }^{a} \text { Valores forne } \\
\text { modernas de Mato Gro } \\
\text { dOLIVEIRA et al. (2005) }\end{array}$ & os pela & "Valores médic & $\begin{array}{l}\text { de usinas } \\
\text { al. (2008); }\end{array}$ \\
\hline
\end{tabular}

O valor obtido para produção energética total no processo de produção do etanol é de $134.400 \mathrm{MJ}^{-h^{-1}}{ }^{-}$. Esse valor é encontrado a partir do produto entre a produtividade da usina, a produção de etanol por tonelada de cana, e o conteúdo energético do etanol.

Aplicando-se à Eq. 1, obtém-se o valor do balanço energético, tomando em vista as informações da Tabela 1, ou seja:

$$
\text { Balanço energético }=\frac{134,000 \mathrm{MJ} \cdot \mathrm{ha}^{-1}}{21.787,8 \mathrm{MJ} \cdot \mathrm{ha}^{-1}}=6,2
$$

MACEDO et al. (2008) avaliaram uma usina sucroenergética de avançada tecnologia localizada no estado de São Paulo e encontraram um valor para o balanço energético de 9,3. Já OLIVEIRA et al. (2005) fizeram uma média das usinas 
sucroenergéticas do Brasil e obtiveram um valor de 3,7 para o balanço energético. MACEDO et al. (2004) encontraram um valor médio de 8,3 para usinas sucroalcooleiras do Brasil. TURDERA (2013) fez um estudo do balanço energético de algumas usinas sucroalcooleiras do sul de Mato Grosso do Sul e obteve o valor de 6,8 como um balanço energético médio das usinas estudadas.

Nota-se que o valor calculado neste estudo está entre os valores encontrados pelos autores citados. A usina sucroalcooleira estudada neste trabalho é considerada de grande porte e moderna, porém, o valor de 6,2 para o balanço energético calculado está abaixo dos valores encontrados por MACEDO et al. (2008) e MACEDO et al. (2004) para usinas também consideradas como modernas. Isso pode indicar que, apesar de ser uma usina moderna, questões como eficiência energética no processo de produção de cana-de-açúcar podem não ser tratadas com a devida importância.

\section{Emissões de GEE do processo de produção do etanol}

A estimativa de emissões de GEE foi feita a partir da aplicação das equivalências de emissões de gases estufa para cada insumo ou processo considerado. Essas equivalências de emissões correspondem à quantidade em quilogramas de $\mathrm{CO}_{2}$ equivalente, lançado por hectare desses gases. A Tabela 2 exibe as equivalências energéticas e as emissões correspondentes dos diversos processos englobados na produção de etanol. Os valores de metano, óxido de nitrogênio, distribuição do etanol, vinhoto, torta de filtro e maquinaria não foram disponibilizados pela empresa, porém, como são uma parcela significativa na contabilidade das emissões da usina, foram considerados os valores médios obtidos por TURDERA (2013) em seu estudo sobre usinas sucroalcooleiras do estado de Mato Grosso do Sul.

TABELA 2- Emissões de $\mathrm{CO}_{2}$ equivalente geradas por hectare com base no consumo de insumos e na produção de resíduos.

\begin{tabular}{|c|c|c|c|}
\hline Componente & $\begin{array}{l}\text { Quantidade } \\
\text { por hectare }\end{array}$ & $\begin{array}{c}\mathrm{CO}_{2 \mathrm{eq}} \\
\text { expelido ou } \\
\text { lançado por } \\
\text { unidade do } \\
\text { componente }\end{array}$ & $\begin{array}{c}\text { Emissões } \\
\left(\mathrm{kgCO}_{2 \mathrm{eq}} \cdot \mathrm{ha}^{-1}\right)\end{array}$ \\
\hline Nitrogênio & $100,00^{\mathrm{a}} \mathrm{kg}$ & $3,97^{b}$ & 397,00 \\
\hline Fosfato $\left(\mathrm{P}_{2} \mathrm{O}_{5}\right)$ & $25,00^{\mathrm{a}} \mathrm{kg}$ & $1,30^{b}$ & 32,50 \\
\hline Óxido de Potássio $\left(\mathrm{K}_{2} \mathrm{O}\right)$ & $140,00^{\mathrm{a}} \mathrm{kg}$ & $0,71^{b}$ & 99,40 \\
\hline Calcário & $4.000^{\mathrm{a}} \mathrm{kg}$ & $0,01^{b}$ & 40,00 \\
\hline Herbicidas & $0^{\mathrm{a}} \mathrm{kg}$ & $25,00^{b}$ & 0 \\
\hline Inseticidas & $0^{\mathrm{a}} \mathrm{kg}$ & $28,00^{b}$ & 0 \\
\hline Diesel combustível & $165,00^{\mathrm{a}}$ litros & $3,08^{b}$ & 508,20 \\
\hline Metano & & & $161^{c}$ \\
\hline $\mathrm{N}_{2} \mathrm{O}$ & & & $465^{\mathrm{c}}$ \\
\hline Distribuição de etanol & & & $227^{c}$ \\
\hline Vinhoto & & & $211,6^{c}$ \\
\hline Torta de filtro & & & $27,3^{\mathrm{C}}$ \\
\hline Maquinaria & & & $1.039,7^{c}$ \\
\hline Total & & & $3.208,7$ \\
\hline
\end{tabular}

Fonte: ${ }^{a}$ Valores fornecidos pela usina estudada; ${ }^{b}$ MACEDO et al. (2008); ${ }^{\circ}$ Valores médios de usinas de Mato Grosso do Sul de TURDERA (2013). 
De acordo com a Tabela 2, estima-se que no processo de produção de etanol, para este caso, foi emitido aproximadamente 3,21 $\mathrm{tCO}_{2 \text { eq }}$ para cada hectare plantado ou, em outras unidades, $42,78 \mathrm{kgCO}_{2 \text { eq }}$ para cada tonelada de cana utilizada. TURDERA (2013) obteve, como média das usinas de Mato Grosso do Sul, um total de emissões de $3.082,24 \mathrm{kgCO}_{2 \mathrm{eq}} \cdot \mathrm{ha}^{-1}$, que é próximo ao encontrado neste estudo. Os valores encontrados por MACEDO et al. (2008) foram de $34,5 \mathrm{kgCO}$ 2eq.tc 1 , que é um valor inferior ao encontrado neste trabalho.

Considerando os 60.000 ha da usina em estudo, estima-se que a emissão

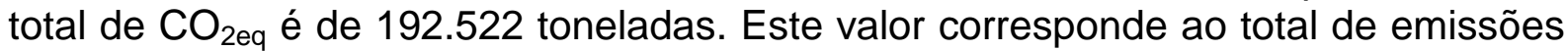
de $\mathrm{CO}_{2 \text { eq }}$ equivalente lançados pela usina durante todo o processo de produção do etanol em toda área de responsabilidade da usina.

A quantidade de álcool produzido ( $A_{\text {produzido }}$ ) pela usina no ano estudado foi de $150.000 \mathrm{~m}^{3}$. Considerando o Poder Calorífico Inferior do etanol como 29,7 MJ.kg 1 e o da gasolina como 44,8 MJ.kg-1 (IPCC, 2014), tem-se que $1 \mathrm{~L}$ de etanol tem 0 mesmo poder calorífico que $0,663 \mathrm{~L}$ de gasolina. Assim, $150.000 \mathrm{~m}^{3}$ de etanol equivalem a $99.450 \mathrm{~m}^{3}$ de gasolina.

Tendo em vista que o fator de emissão da gasolina é de $69.300 \mathrm{kgCO}_{2 \mathrm{eq}} \cdot \mathrm{TJ}^{-1}$ (IPCC, 2014), a densidade de $0,742 \mathrm{kgCO}_{2 \text { eq. }} \mathrm{L}^{-1}$ e o $\mathrm{PCl}$ da gasolina já mencionado, tem-se que a emissão de $\mathrm{CO}_{2 e q}$ para cada litro de gasolina é de:

$$
\begin{aligned}
& \left.\mathrm{ECO}_{2 \text { gasolina }}=44,8 \times 10^{-6}(\mathrm{~T}] \mathrm{kg}^{-1}\right) \times 69.300 \mathrm{kgCO}_{2 \mathrm{eq}} \cdot \mathrm{TJ} J^{-1} \times 0,742 \mathrm{~kg} \cdot \mathrm{L}^{-1} \\
& \mathrm{ECO}_{2 \text { gasolina }}=2,3036 \mathrm{kgCO}_{2 \mathrm{eq}} \cdot \mathrm{L}^{-1}
\end{aligned}
$$

Assim, $99.450 \mathrm{~m}^{3}$ de gasolina repercute em uma emissão de 229.093,02 $\mathrm{tCO}_{2 \text { eq. }}$ Esse total é o teórico que seria emitido caso não houvesse produção de etanol pela usina.

Considerando que houve uma troca da utilização de óleo combustível por bagaço de cana para a produção de eletricidade no processo de cogeração, é possível estimar o total de emissões evitadas pelo não uso deste combustível fóssil.

Geralmente um terço da cana-de-açúcar é bagaço. Assim, considerando os 60.000 ha de plantio da usina e a produtividade de 75 tc.ha ${ }^{-1}$, é possível estimar que 1.500 .000 tc são correspondentes a bagaço. O PCl do bagaço da cana, com $50 \%$ de

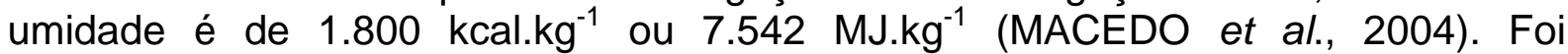
considerando um aproveitamento de $100 \%$ do bagaço para gerar energia excedente. O fator de emissão do óleo combustível é $77.400 \mathrm{kgCO}_{2 \mathrm{eq}} \cdot \mathrm{TJ}^{-1}$ (IPCC, 2014), com $\mathrm{PCl}$ de $9.550 \mathrm{kcal} . \mathrm{kg}^{-1}$ ou 40,014 MJ. kg-1. Considerando os PCls de cada combustível, tem-se que $1 \mathrm{~kg}$ de bagaço de cana equivale a 0,1885 $\mathrm{kg}$ de óleo combustível. Então, a quantidade de óleo combustível necessária para fornecer o mesmo equivalente energético que 1.500 .000 toneladas de bagaço é 282.750 toneladas de óleo combustível. Assim, se esse total de óleo combustível fosse queimado para a produção de energia, ter-se-ia um total de emissões de:

$$
\begin{aligned}
& \mathrm{ECO}_{2} \text { ôleo crnbustivel } \\
& \mathrm{ECO}_{2} \text { óleo combustivel } \\
& =282.750 \mathrm{t} \times 40,014 \mathrm{MJ} \cdot \mathrm{kg}^{-1} \times 77,4 \mathrm{tCO}_{2 \mathrm{eq}} \cdot \mathrm{TJ}^{-1}
\end{aligned}
$$

Assim, a emissão total evitada é a correspondente pelo não uso da gasolina 
como combustível veicular e a correspondente pelo não uso de óleo combustível na caldeira para o processo de cogeração, que resulta em um total de 1.174.793,02 $\mathrm{tCO}_{2 \mathrm{eq}}$ evitadas na safra 2012/2013. Subtraindo o valor das emissões geradas no processo de produção do etanol (192.522 $\mathrm{tCO}_{2 e q}$ ) tem-se um total evitado de 982.271,02 $\mathrm{tCO}_{2 \mathrm{eq}}$.

\section{CONCLUSÕES}

O balanço energético da produção do etanol, nesta usina avaliada, foi positivo e manteve-se entre os valores obtidos por outros autores, constatando que a energia contida no etanol é superior a energia desprendida para sua produção, demonstrando quão vantajosa é a produção de etanol de cana-de-açúcar em comparação a outras culturas. Foi verificada a importância da utilização do bagaço de cana-de-açúcar como combustível para queima na caldeira, já que as emissões evitadas pelo uso deste resíduo em substituição ao óleo combustível se mostraram muito mais relevantes até que as emissões evitadas pelo uso do etanol em substituição à gasolina.

\section{AGRADECIMENTOS}

À CAPES pela bolsa concedida, à UFGD e à UFPR pelo apoio e estrutura, $\mathrm{e}$ à usina pelo fornecimento dos dados.

\section{REFERÊNCIAS}

ABRAMOVAY, R. Biocombustíveis, A energia da controvérsia. São Paulo: senac, 2009.

CLAUDINO, E. S.; TALAMINI, E. Análise do ciclo de vida (ACV) aplicada ao agronegócio: uma revisão de literatura. Revista Brasileira de Engenharia Agrícola e Ambiental, Campina Grande. Vol. 17, n. 1 (2012), p.[77]-85, 2012. Disponível em: < http://hdl.handle.net/10183/112124>. doi: http://dx.doi.org/10.1590/S141543662013000100011

COELHO, W. L. V.; DA SILVA, F. S.; DALLACORT, R.; \& CARNEIRO, P. A. V. Análise do potencial de geração de energia elétrica a partir dos resíduos do setor sucroenergético no estado de Mato Grosso em diferentes cenários produtivos. Revista Brasileira de Energias Renováveis, v. 5, n. 2, 2016. Disponível em: <http://revistas.ufpr.br/rber/article/view/46305>. doi: http://dx.doi.org/10.5380/rber.v5i2.46305

IPCC. Climate Change, 2014. Disponível em: <http://www.ipcc.ch/report/ar5/wg1/\#.Uv15QfldX9U>. Acesso em 13 fev. 2014.

MACEDO, I. C.; JOAQUIM E. A.; SEABRA, J. E. A. R. S. Green house gases emissions in the production and use of ethanol from sugarcane in Brazil: The 2005/2006 averages and prediction for 2020. Biomass \& Bioenergy, 2008. Disponível em: <http://www.sciencedirect.com/science/article/pii/S0961953407002310>. doi: http://dx.doi.org/10.1016/j.biombioe.2007.12.006 
gas emissions in the production and use of fuel ethanol in Brazil. São Paulo, 2004. Disponível em: www.unica.com.br/i_pages/files/pdf_ingles.pdf

OLIVEIRA, L. M.; SERRA, J. C. V.; OLIVEIRA, K. B. M; Balanços energéticos da produção de etanol para diferentes matérias primas. Geoambiente On-line, n. 22, 2014. Disponível em: <http://revistas.jatai.ufg.br/geoambiente/article/view/32268>. doi: http://dx.doi.org/10.5216/revgeoamb.v0i22.32268

OLIVEIRA, M. E. D. D.; VAUGHAN, B. E.; JR., E. R. Ethanol as Fuel: Energy, Carbon Dioxide Balances, and Ecological Footprint. BioScience , v. 55, p. 593-602, Julho 2005.2 Disponível em: <http://bioscience.oxfordjournals.org/content/55/7/593.full>. doi: 10.1641/00063568(2005)055[0593:EAFECD]2.0.CO;2.

SANTOS, F. A.; QUEIRÓZ, J. D.; COLODETTE, J. L.; FERNANDES, S. A.; GUIMARÃES, V. M.; REZENDE, S. T. Potencial da palha de cana-de-açúcar para produção de etanol. Química Nova, v. 35, n. 5, p. 1004-1010, 2012. Disponível em: $<$ http://www.scielo.br/scielo.php?script=sci_arttext\&pid=S010040422012000500025>. doi: http://dx.doi.org/10.1590/S0100-40422012000500025.

TURDERA, E. M. V. Energy balance, forecasting of bioelectricity generation and greenhouse gas emission balance in the ethanol production at sugarcane mills in the state of Mato Grosso do Sul. Renewable and Sustainable Energy Reviews, p. 582488, 2013. Disponível em: < http://www.sciencedirect.com/science/article/pii/S1364032112006697>. doi: http://dx.doi.org/10.1016/j.rser.2012.11.055 